\title{
Microscopic Simulation Approach to Capacity Analysis of Bus Rapid Transit Corridors
}

\author{
Abdul Jabbar Siddique, Ata M. Khan \\ Carleton University
}

\begin{abstract}
While a transitway can be built as an access-controlled, two-way rapid transitfacility outside the Central Business District (CBD), in the CBD, initially, the Bus Rapid Transit (BRT) service has to be based on exclusive bus lanes due to right-of-way, monetary, and other constraints. The strategy of providing Bus Rapid Transit on exclusive bus lanes in urban corridors is receiving policy attention. However, detailed studies on exclusive bus lane capacity for BRT operation in the CBD of a city have been scarce. In this research, using NETSIM as a microsimulator, BRT corridors in Ottawa (Canada) were investigated in terms of their capacity to handle high volumes of transit buses. For these corridors, scenarios incorporating 2021 traffic were analyzed for choke condition and the results were compared with the base case condition representing year 2001 traffic environment. Based on the results of network performance, conclusions were drawn on the capacity of $B R T$ corridors.
\end{abstract}

\section{Introduction}

Bus Rapid Transit (BRT) is increasingly viewed as an affordable and effective mode to increase mobility (BRT newsLane 2005). BRT often benefits from an exclusive busway (also called a transitway), which can be provided in a number of ways outside the Central Business District (CBD). The transitway can be built on its 
own right-of-way, or it can be accommodated in a freeway corridor. To expedite BRT development, the transitway can be built outside the CBD first. In the CBD, due to many constraints including space and money, the BRT service can be provided on exclusive lanes. This BRT development strategy was followed in Ottawa (Canada).

Realizing the importance of transit operation in the future growth of Ottawa's downtown (City of Ottawa 2003), a very important question for City policy makers and transportation planners is determining the state beyond which throughput of transit buses in exclusive bus lanes of BRT corridors could not be increased without making facility design changes. However, reliable and well researched information on capacity and service factors of BRT operation on exclusive bus lanes in a downtown environment is scarce. Therefore, this research was designed to answer this very question.

\section{Study Area and Research Challenge}

Figure 1 shows a part of the Ottawa downtown street network including two important public transit corridors. The study area encompasses these transit corridors, i.e., Albert and Slater streets, that facilitate West- and East-bound BRT operation, respectively. These corridors offer one-way traffic operation with single bus-only lanes in a mixed traffic environment and connect with East and West transitways outside the CBD. The link/node diagram (Figure 2) shows the streets with transit lanes and eight crossing streets. Total length of transit corridors between Elgin and Bronson (i.e., in the East-West direction) is $1.3 \mathrm{~km}$. Block lengths in the north-south direction, i.e., between Albert and Slater streets, are approximately $80 \mathrm{~m}$. However, in the east-west direction, it varies between $135 \mathrm{~m}$ and $255 \mathrm{~m}$, approximately.

The research challenge was to determine the choke level of bus traffic for exclusive lanes, which is defined in this research as a state in which throughput of transit buses could not be increased further under given traffic operating conditions. $n$ essence, choke level is the maximum throughput or capacity under prevailing conditions. For the Ottawa CBD case, it was intended to find maximum throughput of buses that can be accommodated on exclusive bus lanes of BRT corridors under various scenarios that reflect 2021 traffic operating conditions. 
In addition to finding answers for the Ottawa CBD bus corridors, it is of research interest to provide sufficient information on this topic so that other jurisdictions can use the methodology and findings.

Figure 1. Study Area and the Street Network in Downtown Ottawa

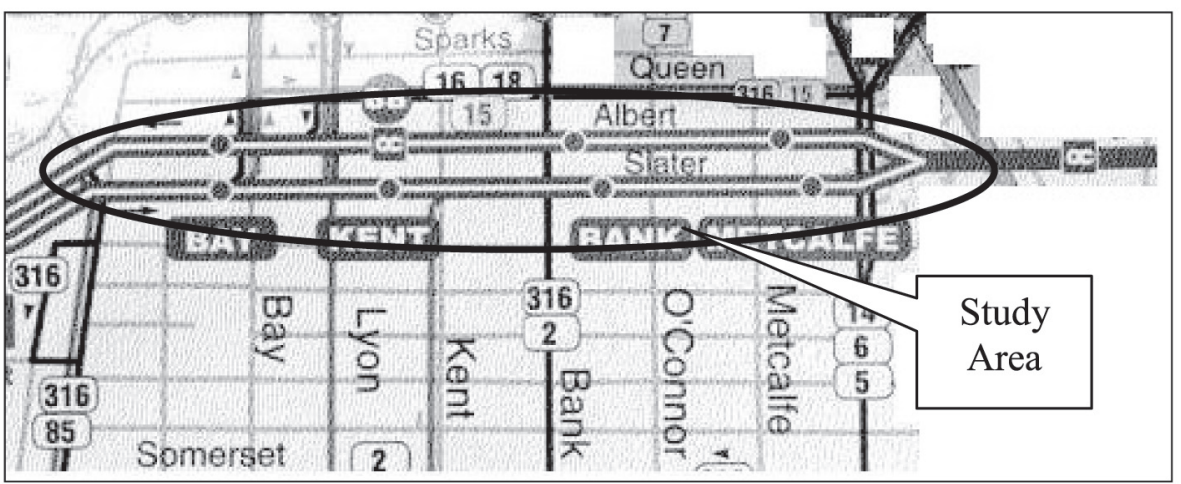

\section{State of Knowledge in Bus Corridor Capacity}

Literature review shows little information on bus flow capacity of an arterial with an exclusive bus lane for BRT operation in the CBD of a city. This deficiency was addressed to some extent by St. Jacques and Levinson (1997) in a study "Operational Analysis of Bus Lanes on Arterials," which contains guidelines for estimating bus lane capacities and speeds along arterials. Kittelson \& Associates (1999) contributed definitions, principles, practices, and procedures in the Transit Capacity and Quality of Service Manual (TCQSM).

A few authors provided observations on bus lane capacity or bus headways, mostly for uninterrupted flow conditions. For example, in case of New Jersey's Lincoln Tunnel, 735 buses are reported to have operated on exclusive right-of-way during morning peak hour in peak direction (Kittelson \& Associates 1999a).

Some South American cities reported bus volumes for exclusive lanes (City of Bogotá 1996, City of Carolina 2002). However, the operational features of the corridors were not clearly described. For instance, in the City of Bogotá, Columbia, a higher volume of buses ( 630 buses/hr in two lanes) was reported than the maximum number of buses calculated from simulation results (City of Bogotá1996). In 
Journal of Public Transportation, 2006 BRT Special Edition

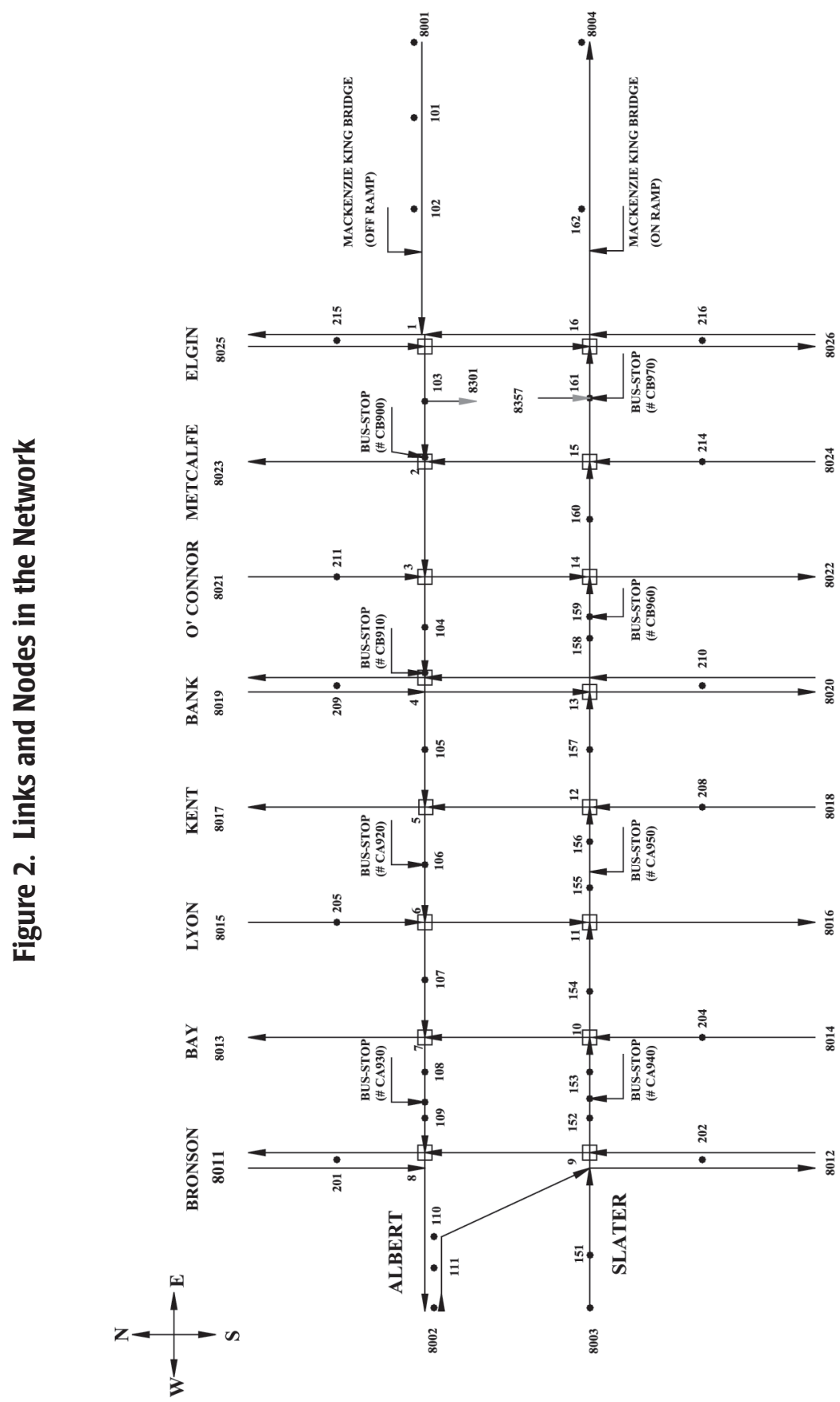


the case of Ottawa, the BRT is operating below capacity in the CBD corridors as well as outside the CBD. The 2001 highest bus volume in the CBD part of BRT was 225 buses/hr. Also, 225 buses/hr have been reported on the West Transitway.

In short, real life North American examples of BRT operation on exclusive bus lanes in interrupted flow environment operating at or above capacity are not available. From a capacity analysis perspective, there is little information on high volumes of buses operating in the form of a platoon in a CBD environment. Regarding capacity of a bus lane, there is not much literature available except the one item referenced earlier (St. Jacques and Levinson 1997), in which the authors noted the practical problems associated with high volume transit operations that need to be resolved while calculating capacity of a bus lane operating under interrupted flow conditions in a CBD.

The Highway Capacity Manual (HCM 2000) procedure, due to its rather coarse nature, is of limited use in the study of capacity and level of service of bus transit corridors in a CBD environment.

\section{Study Methodology: The Microsimulation Approach}

Due to the level of detailed analysis that was essential for finding answers, the dynamic microscopic analysis approach was adopted. Past research concluded that there is a need for the use of a microsimulation approach to study BRT planning, design and operational problems (Multisystems, Inc. 2000). A simulation tool is considered ideal for public presentation, evaluation of before and after studies, and routine planning and operations analysis. It offers users the opportunity to observe animated traffic conditions and evaluate alternative scenarios for roadway and signal system improvements in various traffic environments. Further, it is considered more practical than a field experiment (Federal Highway Administration 2001).

In this research, NETSIM, a stochastic microscopic traffic simulation tool (version 5.1) was employed to model and simulate BRT system operations in the downtown of Ottawa. This simulator can update the state of each vehicle and the system under study on a second-by-second basis (Liu et al. 1996). Behavior of vehicles is governed by car-following, queue discharge and lane switching logics (Transportation Research Board 2000). NETSIM has the capability to simulate transit bus operations up to a maximum of 2,000 buses. A wealth of data in the 
form of measures-of-effectiveness (MOE) is accumulated at the end of each simulation run.

In NETSIM, the car-following logic differentiates the operation of private vehicles from a public transit bus that is supposed to service passengers at bus stations. Kinematic properties of each vehicle such as speed and acceleration as well as its status (i.e., whether it is in a queue or moving) are also determined. Delays caused to the turning vehicles at intersections due to pedestrian traffic are also modelled in the network to represent real time traffic operations.

\section{Network and Traffic}

The 2001 operating conditions were regarded as the base-case scenario. To determine choke level in the network, auto traffic was projected to year 2021. Supply of transit buses was maximized by lowering mean headways and providing additional green time along transit corridors only until delays experienced by auto traffic movements on links intersecting transit streets reach a Level of Service $E$ or F. In this research, BRT operation was studied under passive priority measures in which fixed time plans of traffic signals were used and additional green time was allocated to transit streets. According to available information, the transit bus pre-emption signal strategy in the $\mathrm{CBD}$ is not regarded to be more effective than passive priority measure due to short block lengths and high volume of buses (Dillon M.M. 1993). Salient features of the study area are shown in the Table 1. In 2001, there were two types of buses operating in the network, i.e., standard bus (12 $\mathrm{m}$ long) and articulated bus (18 $\mathrm{m}$ long). Their proportions were 84 percent and 16 percent, respectively. There were eight bus stop locations in the study area, among which some are mid-block stops while others are near-side stops (located immediately before an intersection). Hourly volume of buses for each bus stop location is shown in Table 2.

\section{Table 1. Salient Features of the Study Area}

\begin{tabular}{|c|c|c|c|}
\hline No. of Traffic signals & 16 & Cycle Lengths & 60 and $120 \mathrm{sec}$ \\
\hline \multicolumn{2}{|c|}{ Pedestrian volume at intersection: } & \multicolumn{2}{|c|}{ Transit bus volume: } \\
\hline - Highest & 2177 & - Albert Street & $225 / \mathrm{hr}$ \\
\hline - Lowest & 130 & - Slater Street & $159 / \mathrm{hr}$ \\
\hline \multicolumn{2}{|c|}{ Passenger activity on any single bus station: } & \multicolumn{2}{|c|}{ Total passenger activity on: } \\
\hline - Highest & 2183 (On + Off) & - Albert Street & $6823($ On + Off) \\
\hline - Lowest & 430 (On + Off) & - Slater Street & 4841 (On + Off) \\
\hline
\end{tabular}


Table 2. Hourly Volume of Buses at Bus Stations

\begin{tabular}{|c|c|c|c|c|c|}
\hline \multicolumn{3}{|c|}{ Albert Street } & \multicolumn{3}{c|}{ Slater Street } \\
\hline S. No. & Bus Stop \# & Volume (vph) & S. No. & Bus Stop \# & Volume (vph) \\
\hline 1 & CB -900 & 218 & 1 & CA - 940 & 159 \\
2 & CB -910 & 217 & 2 & CA - 950 & 147 \\
3 & CA -920 & 225 & 3 & CB -960 & 149 \\
4 & CA -930 & 214 & 4 & CB - 970 & 148 \\
\hline
\end{tabular}

Dwell Time data are collected regularly by OC-Transpo using Automatic Passenger Counters (APC) installed on various transit buses. These data were utilized to simulate Base Case and other scenarios of bus operation across transit corridors. Table 3 shows average dwell times at respective bus stop locations.

Table 3. Dwell Time (sec) of Buses at Bus Stations

\begin{tabular}{|c|c|c|c|c|c|}
\hline \multicolumn{3}{|c|}{ Albert Street } & \multicolumn{3}{c|}{ Slater Street } \\
\hline S. No. & Bus Stop \# & $\begin{array}{c}\text { Average Dwell } \\
\text { Time (sec) }\end{array}$ & S. No. & Bus Stop \# & $\begin{array}{c}\text { Average Dwell } \\
\text { Time (sec) }\end{array}$ \\
\hline 1 & CB - 900 & 11 & 1 & CA - 940 & 5 \\
2 & CB - 910 & 12 & 2 & CA - 950 & 10 \\
3 & CA - 920 & 10 & 3 & CB - 960 & 9 \\
4 & CA - 930 & 3 & 4 & CB - 970 & 9 \\
\hline
\end{tabular}

Note: Data shown in tables above are for year $2001 \mathrm{AM}$ peak hour (7:30 am to 8:30 am)

\section{Description of Scenarios}

Three types of scenarios were defined, as shown in Figure 3. Case A represents the Base Case scenario (2001 traffic operating conditions). In Case B, auto traffic was projected to year 2021 but signal control settings were kept the same as in the base case. The supply of transit buses was increased until choke conditions appeared in the network. In Case C, 2021 auto traffic was assumed, and additional green time was assigned to transit streets. The supply of transit buses was again maximized until choke conditions appear within the network. Figures 4 and 5 show green/ cycle $(\mathrm{g} / \mathrm{C})$ ratios for Cases $\mathrm{A}, \mathrm{B}$ and $\mathrm{C}$ at each intersection along Albert and Slater Streets, respectively. The MOE obtained from Cases B \& $C$ were compared with Base Case A condition. 


\section{Figure 3. Scenario Categories and Description}

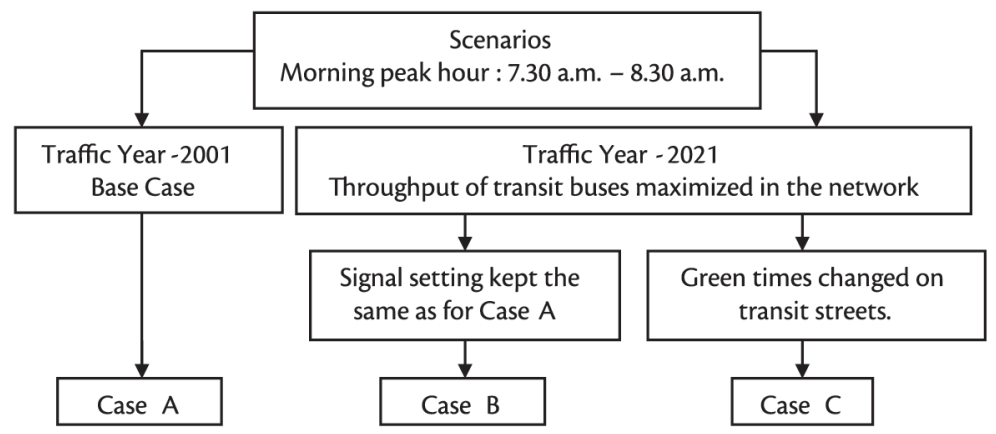

Figure 4. (g/C) Ratios along Albert Street in Cases A, B and C

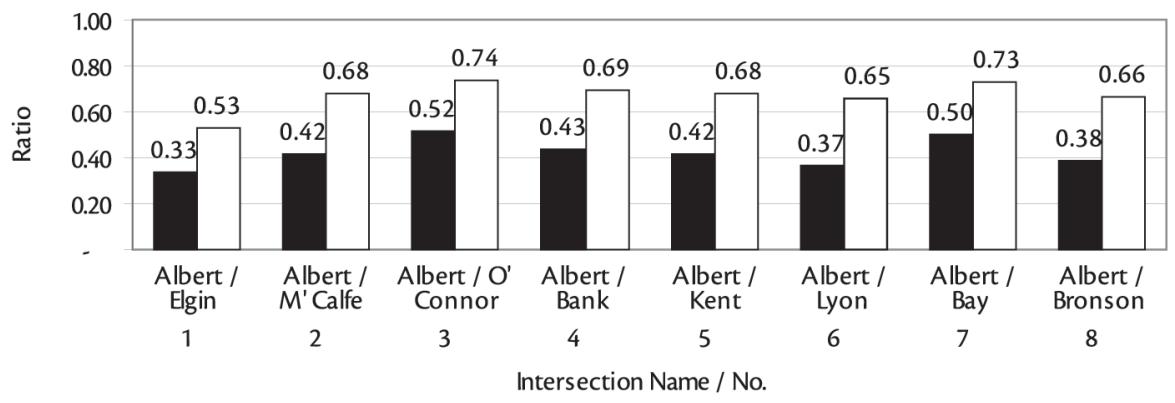

(g/C) Ratio in Cases "A and B" $\quad \square(\mathrm{g} / \mathrm{C})$ Ratio in Case "C"

Figure 5. (g/C) Ratios along Slater Street in Cases A, B and C.

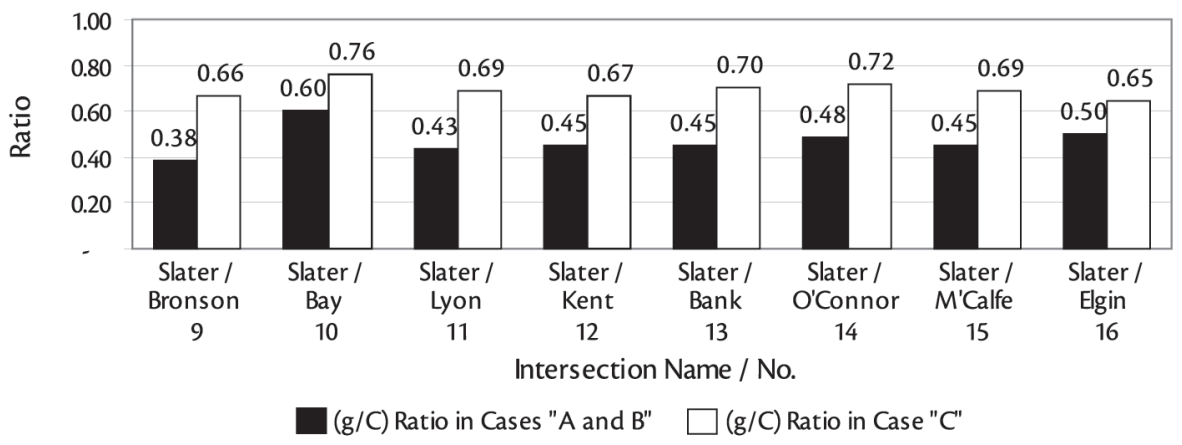




\section{Simulation Process}

Because of the stochastic nature of the simulator (NETSIM), the MOE obtained from a simulation run are the outcome of a specific set of random number seeds. A particular set of random number seeds may yield very conservative or avantgarde results. Therefore, simply relying on the results of a single simulation run of a scenario might be misleading. To gain a better understanding of network performance, each scenario was simulated 10 times, using different sets of random number seeds. The results of all the simulations were averaged and used for further calculations and analysis.

\section{Simulation Results}

The number of buses generated in all the three case scenarios reflects the exclusive bus lane operation in the CBD of Ottawa. As noted earlier, in Case B, while keeping all the operating characteristics same as in Case A, supply of buses along transit corridors was maximized by reducing the mean headway. An analysis of bus operation at mean headway of 8 seconds suggested that choke condition did not occur. Therefore, the headway was reduced to 7 seconds/bus. At a mean headway of 7 seconds/bus for Case B, choke conditions appeared at upstream side of Albert and Slater streets, shown in Figure 2 by links (101-1) and (151-9), respectively. At this headway level, throughput of buses was recorded as $442 / \mathrm{hr}$ and $449 / \mathrm{hr}$ on upstream links of Albert and Slater streets, respectively. These are shown in Figure 6 along with base case scenario (Case A).

\section{Figure 6. Number of Transit Buses on Albert and Slater Streets in Cases $A$ and $B$}

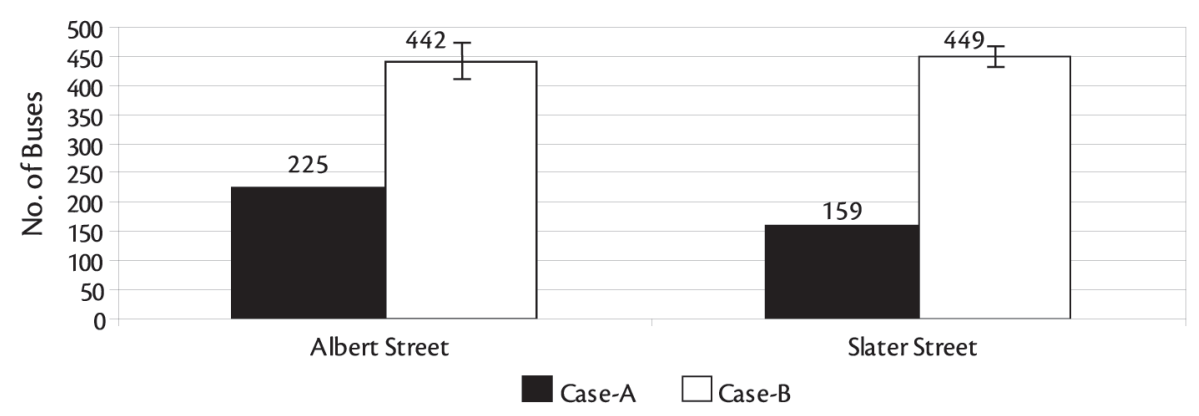

* Note: Symbol 'I' shown in this article represents Standard Deviation of 10 simulation results. 
It is important to note that in Case B, in theory at a 7-second/bus mean headway, 514 buses/hr (3600/7) were supposed to be generated during one hour simulation period. Similarly, in Case C, at a mean headway of $5 \mathrm{sec} /$ bus along with a significantly high green time (50 sec added to the base case) along Albert and Slater corridors, the number of buses discharged at the upstream links of these corridors were only 486 and 494, respectively, as opposed to 720 buses (i.e. 3600/5) that were supposed to be generated in a one-hour period. According to TCRP Report 26 (1997), this is an indication of the choke point and is explained in the next paragraph.

Figure 7 shows a comparison of buses generated in Case B vs. Case $C$ at different additional green times. The total discharge being well below the flow rate of buses defined as input in both Case $B$ and Case $C$ suggested that the capacity of exclusive bus lane in each case was reached. This observation is in accordance with the TCRP Report 26 (St. Jacques and Levinson 1997). The authors state that, "Two measures of performance output indicated the point at which capacity was reached: (1) simulated average bus speeds dropped significantly and (2) the number of buses serviced at the bus stop was less than the number of buses input as the bus flow rate. These two measures indicated a point at which no greater flow rate of buses would be achieved along the arterial and where buses queued excessively at the bus stop or at upstream signals."

When animation results generated by NETSIM for these cases were observed on screen, it indicated a long queue of buses on upstream links (101 - 1) and (151

\section{Figure 7. Transit Buses on Albert and Slater Streets at Different Green Times}

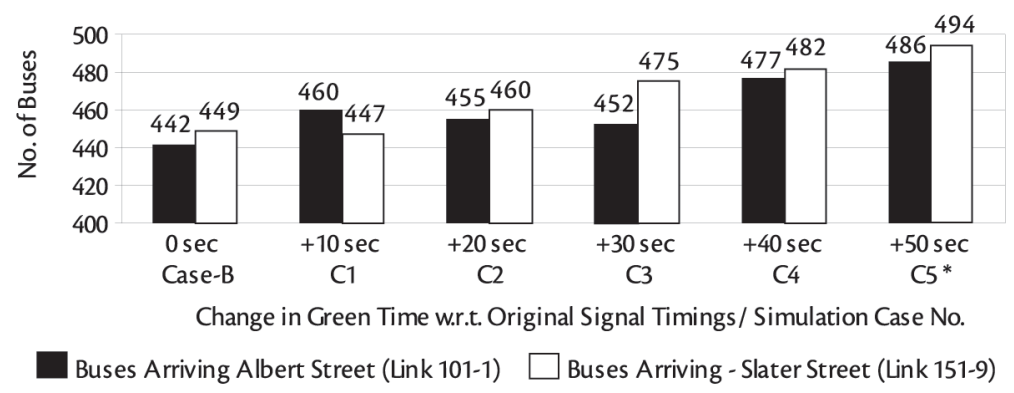


- 9). One hour simulation results also showed the average queue on these links as 10 and 8 vehicles, respectively. These queues of buses were unable to be served completely during a green phase of signal cycle. Thus, traffic flow was adversely affected, resulting in lower speed, and higher delay and travel time. It is important to mention that these upstream links are serving as a main supply source of transit buses to Albert and Slater streets. If these upstream links operate at capacity, the supply of transit buses cannot be increased at the downstream side of transit corridors.

\section{Analysis of Results}

To further understand the saturated state of bus transit operation in exclusive lanes at upstream links of Albert and Slater streets, results generated by NETSIM in all three case scenarios were analyzed. Among the measures selected for analysis and comparison were average speed, average delays, travel time (sec/bus) and average and maximum queues. These are commonly used measures for estimating effectiveness at signalized intersections (Roess, Prassas, and McShane 2004). Due to space limitations, only speed and delay results are shown in Figures 8 to 11 .

Results shown in each of these figures represent output in two different patterns. Under the first pattern, results are compiled and shown for the first 10-minute period in which output data are collected at every 10 -sec interval. In this way, we get a complete understanding of the fluctuations happening in transit operation due to the presence of control signals in the network. In the second pattern, results are compiled for rest of the 50-minute simulation period in which data are gathered at every 10 -minute interval.

It can be observed from Figures 8 and 9 that, in Case A, average bus speed along upstream links (101-1) on Albert and (151-9) on Slater streets get stabilized within first three/four minutes period and continue to operate at around $29 \mathrm{~km} / \mathrm{hr}$ and $26 \mathrm{~km} / \mathrm{hr}$, respectively, throughout the one hour simulation period.

The same phenomena can be observed (in Case A) for bus total delays shown in Figures 10 and 11. However, in Cases $B$ and $C$, bus operation is entirely opposite to Case $A$ and a sudden drop in average bus speed is seen during the first 10-minute period. The overall decrease in average speeds in Cases $B$ and $C$ is more than 70 percent (as compared to the base case) on both Albert and Slater streets. The obvious outcome of this reduction in average speeds is higher delays and longer travel times. 


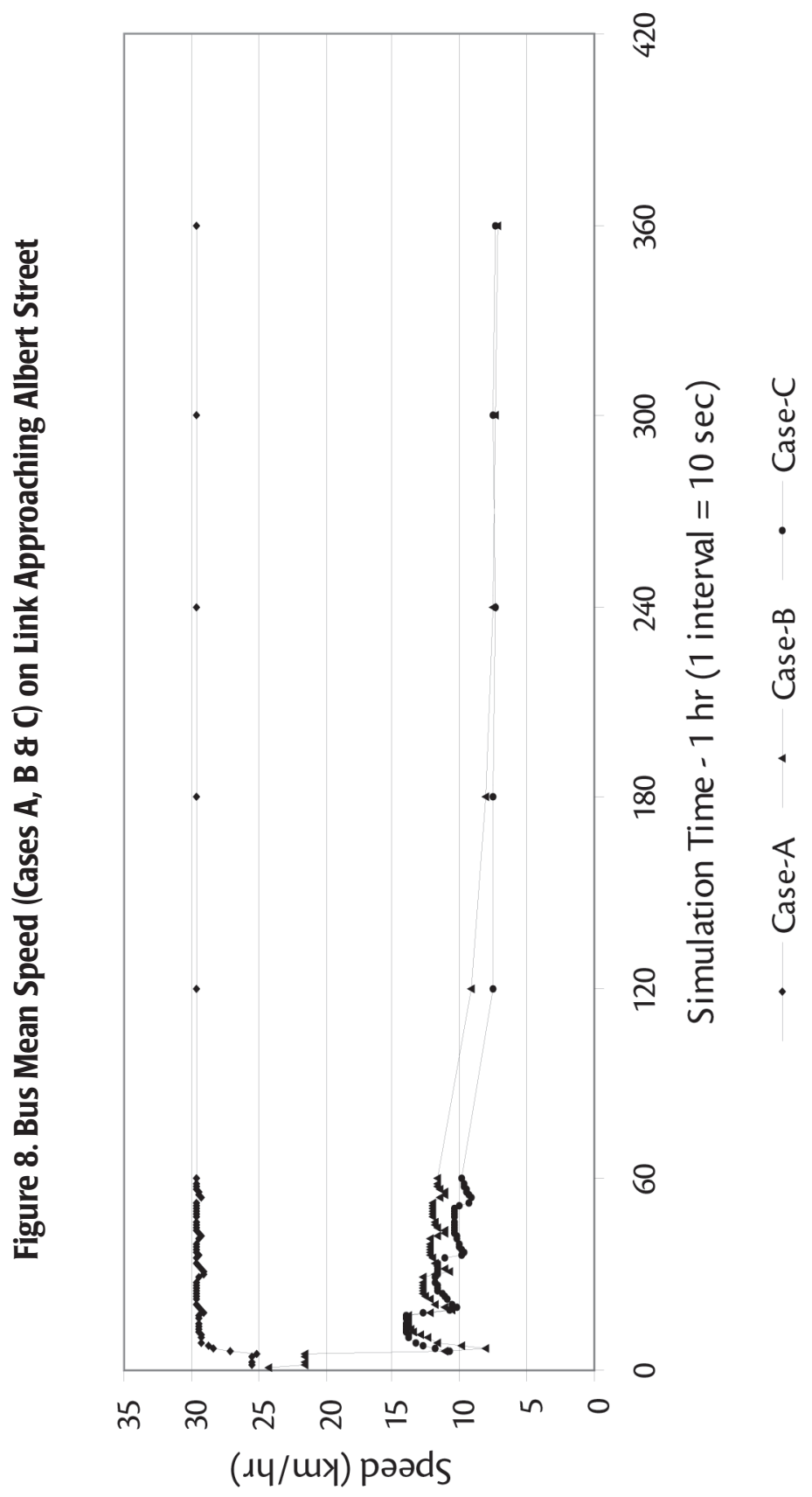




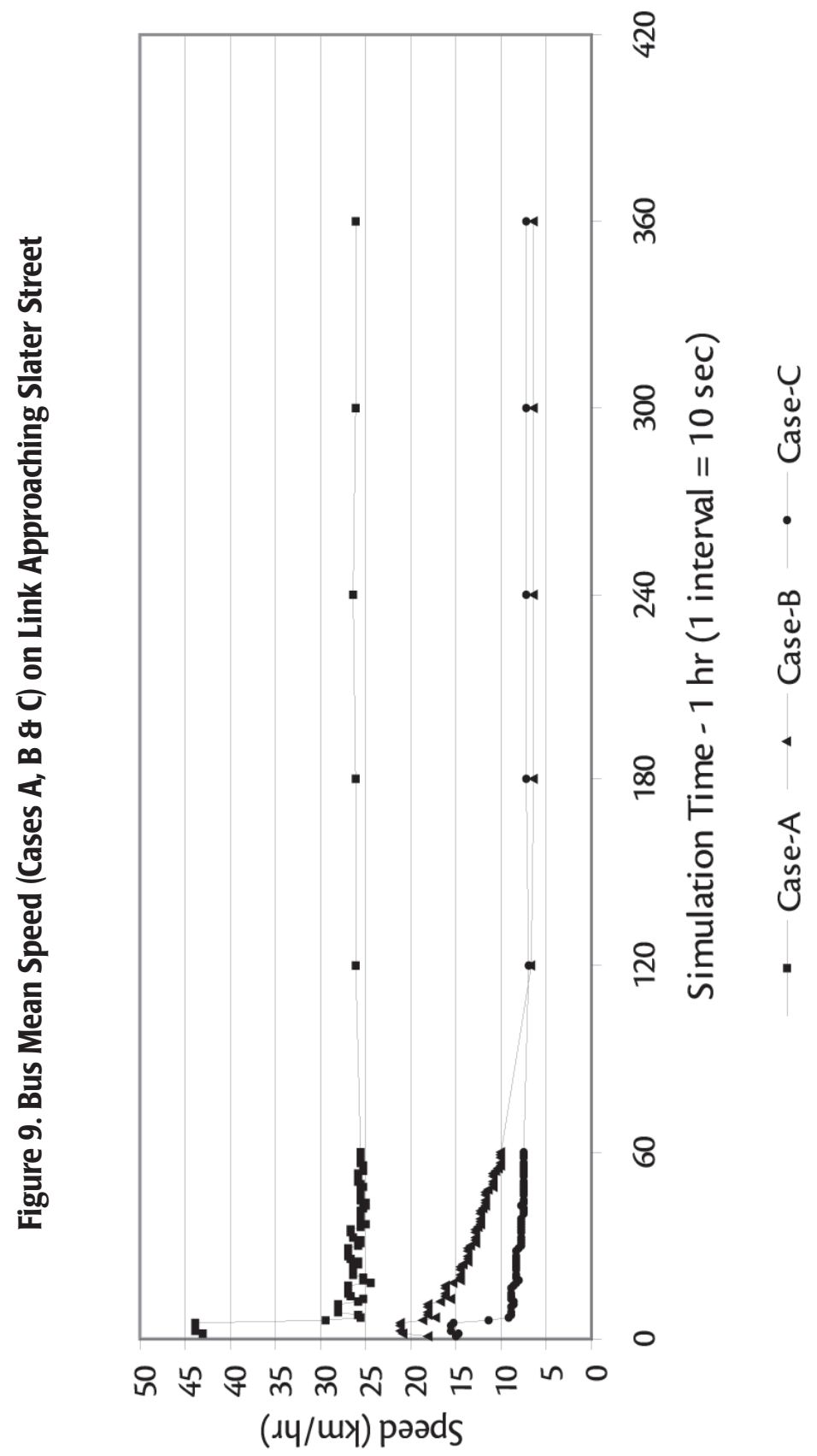




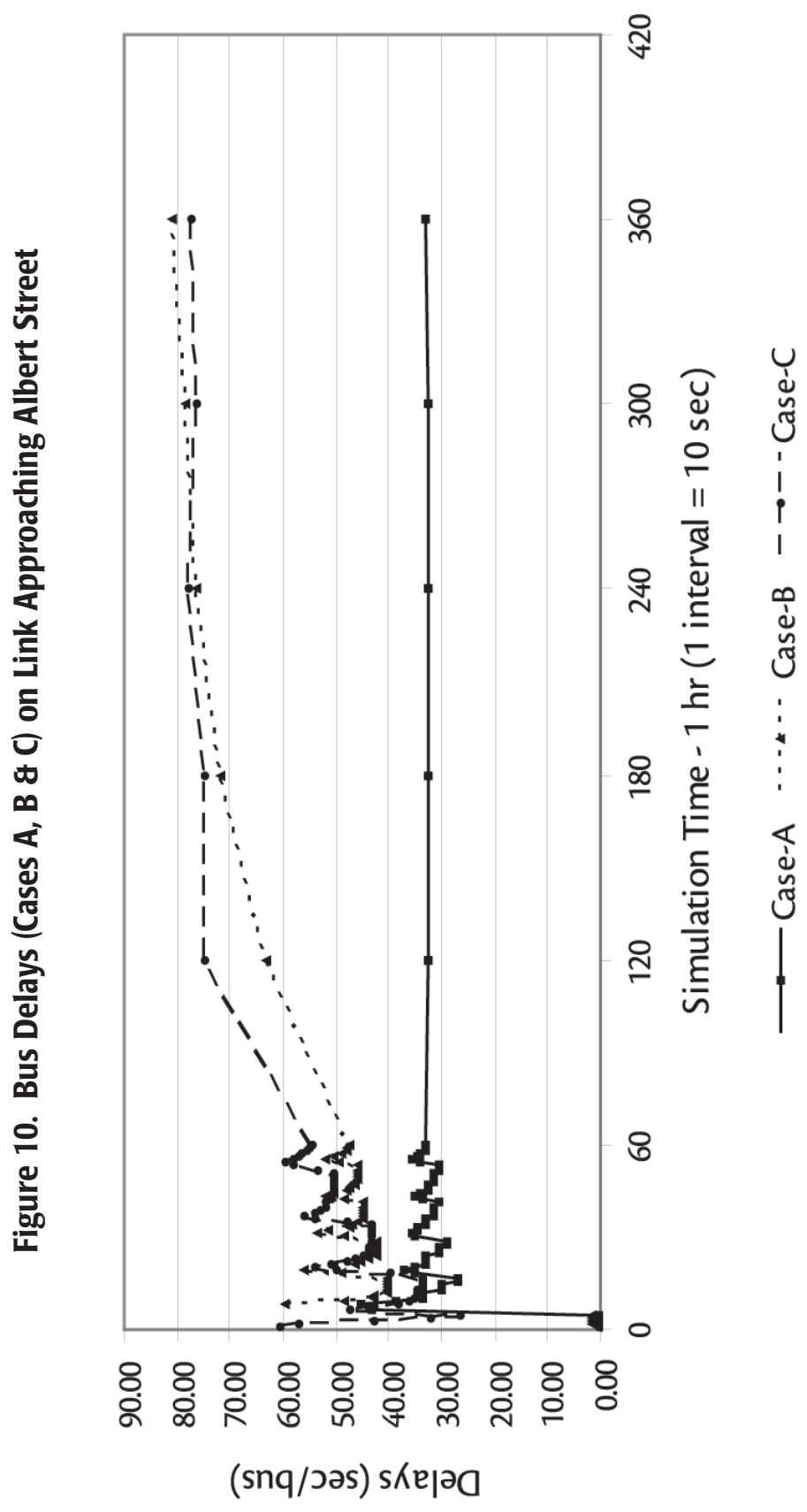




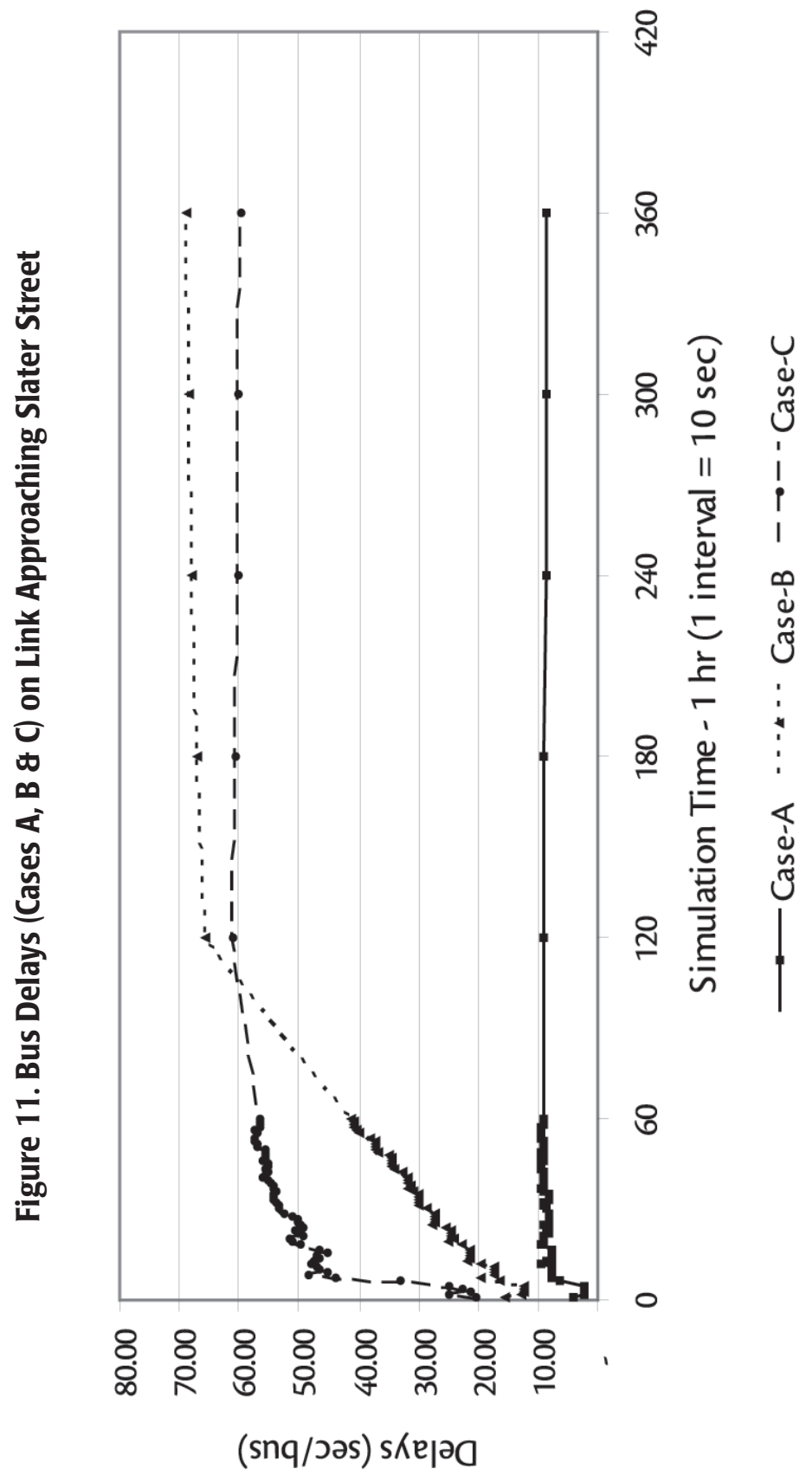


It is important to note that the queues of buses generated had already occupied the entire length defined for upstream links (101-1) on Albert and (151 - 9) on Slater streets. Regarding bus delays, we can notice from Figures 10 and 11 that these are continuing to increase with the passage of time in Cases $B$ and $C$ as opposed to Case A. A similar pattern was observed in bus travel times (not shown here due to space limitations).

Speed results were also plotted against bus delays as well as bus travel times. A regression analysis was also carried out in each of these cases. The regression equations and correlation coefficients $(r$ ) between two parameters (speed and bus delays or bus travel time) were calculated. As expected, a negative slope of regression lines showed an inverse relationship between the two parameters. High values of " $r$ " were found, which suggest a strong correlation between the two parameters. The speed vs. delay plots and regression equations are not shown in this paper due to space limitations.

From a network perspective, it is useful to assess the impacts of increasing bus volume at the expense of other traffic in the network. This can be achieved by the study of advantages of Case B over Case C (Table 4). These results indicate that as compared to Case $B$, in Case $C$ higher bus throughputs are achieved at the expense of adverse effects on the overall network operations.

\section{Table 4. Comparative advantage of Case-B over Case-C (at Network Level)}

\begin{tabular}{|c|c|c|c|}
\hline MOE $^{1}$ & $\%$ & MOE $^{1}$ & $\%$ \\
\hline Move Time & $15.2 \%$ higher & Total Veh-km travelled & $15.2 \%$ higher \\
Delay Time & $47 \%$ lower & Average speed & $80.7 \%$ higher \\
Total Time & $36.3 \%$ lower & Minutes $/ \mathrm{km}$ of Delay Time & $53.3 \%$ lower \\
Move/Total ratio & $82.3 \%$ higher & Minutes $/ \mathrm{km}$ of Total Time & $45.2 \%$ lower \\
Stop Delays & $54 \%$ lower & Total Fuel consumption & $12.8 \%$ lower \\
Queue Delays & $54.4 \%$ lower & - & - \\
\hline
\end{tabular}

${ }^{1} \mathrm{MOE}:$ Measure of Effectiveness 


\section{Conclusions}

Following are the main conclusions of this research.

1. Case B can accommodate 442 and 449 buses in exclusive bus lanes on Albert and Slater corridors, respectively, along with year 2021 auto traffic traversing through other lanes of these corridors. At this volume level, exclusive bus lanes will saturate at upstream sides of Albert and Slater streets represented by links (101-1) at intersection \# 1 and link (151-9) at intersection \# 9, respectively.

2. In Case $C$, an increase in green times of up to $+30 \mathrm{sec}$ (in addition to original signal times) along transit corridors attracts less than 6 percent of additional bus volume on transit corridors, as compared to Case B (with no additional green time on transit streets). Similarly, increase in green times up to +50 sec (in addition to original signal times) accommodates 486 and 494 buses on Albert and Slater streets, respectively, i.e., an increase of 10 percent on each of the streets. At this point most of the traffic movements on links intersecting transit streets will be operating at a LOS E or F, representing choke conditions in the network.

3. Capacity estimates of exclusive bus lane obtained from simulation results vis-à-vis from the Highway Capacity Manual (HCM) 2000 procedure show much difference. In Case B, capacity resulting from microsimulation is 55 percent and 35 percent higher on Albert and Slater streets, respectively, as compared to the figures calculated from HCM 2000. Similarly, in Case C, it is 22 percent and 11 percent higher on Albert and Slater streets, as compared to HCM 2000 results.

4. At saturated conditions, average speeds on upstream link (101 - 1) along Albert Street in Cases B and C will drop by 75 percent, bus total delays and bus travel time will increase by more than 135 percent and 96 percent, respectively, and average queue length will rise by 400 percent. Further, maximum queues will grow from 8 to 15 or higher on same links. Similarly on upstream link (151 - 9) along Slater Street, in Cases B and C, average bus speed will reduce by more than 72 percent, total bus delays and bus travel time will increase by more than 578 percent and 264 percent, respectively, and maximum queues will rise by 450 percent. Further, average bus queues will grow from 0 to 8 buses on same link.

5. Based on year 2001 average occupancy figures of transit buses, which is 32.5 persons/bus at the upstream links of Albert and Slater Streets, up to 28,960 
passengers in Case B and 31,850 passengers in Case $C$ can be transported to the downtown core through transit operation on Albert and Slater streets only.

6. Operational advantages of Case B over Case $C$ suggest that, if BRT has to operate on exclusive lanes in the CBD, allocation of additional green time to bus streets at the expense of other traffic is not effective from the overall system perspective. Here, all the vehicles and the study area network define the system. Effectiveness was gauged using a number of measures including speed, time, delay, km traversed, fuel consumption, and emissions.

\section{Recommendations}

1. Although the simulator NETSIM used in this research is reasonably well developed, further improvement can be made.

(a) Average dwell time of buses at each bus station may vary from real time situations, as many buses have different dwell times. Routes with higher dwell time impede transit traffic at upstream side. In NETSIM, a provision should be developed so that dwell times are defined according to the route demands instead of an average dwell time value applicable to all routes in the system.

(b) In NETSIM, option of two or more exclusive bus lanes should also be provided.

2. Since increase in green time along transit corridor as in Case $C$ is not significantly increasing the throughput of transit buses as compared to Case B, rather it is causing excessively high delays to traffic movements on intersecting streets, it is, therefore, recommended to continue transit operations at existing cycle lengths.

3. Another analysis incorporating two bus lanes and additional bus stations located at suitable points across the width of the corridor should be carried out.

4. Skip Stop strategy can be applied in future but it needs further study regarding the effect on dwell times (which might increase on some bus stops) and how to educate people, etc.

5. All high-floor buses can be replaced with low-floor buses, and an automated fare collection system can be used in order to speed up dwell times 
6. This study can be further extended to examine the prospects of using a larger share of the fleet comprised of larger vehicles. Such a study may provide the planners an insight into the relative vehicle performance of standard sized versus large BRT vehicles.

\section{Acknowledgements}

The Natural Sciences and Engineering Research Council of Canada (NSERC) provided financial support for research reported in this article. The authors gratefully acknowledge the availability of OC Transpo data used in this research. The views are those of the authors.

\section{References}

BRT newsLane. 2005. BRT year in review: Looking back on 2005. Vol.4, No.5, WestStart-CALSTART, supported by the Federal Transit Administration, USA.

City of Bogotá. 1996. Master Transportation Plan for Bogotá, (JICA)

City of Carolina. 2001-2002. Department of City and Regional Planning. Carolina Transportation Program, Report.

City of Ottawa. 2003 Ottawa Transportation Master Plan.

Dillon M.M. 1993. Review of the traffic signal operation on the Central Area Transitway. Final Report, Ottawa.

Federal Highway Administration (FHWA). 2001. CORSIM User's Guide - version 5.0. Office of Operations Research, Development and Technology, Washington, D.C.

Institute of Transportation Engineers. 1986. Urban traffic congestion: What Does the Future hold? ITE Publication No. IR-040, Washington, D.C.

Kittelson and Associates, Inc. 1999. TCRP web document 6 - Transit capacity and quality of service manual. Prepared for Transit Cooperative Research Program, Transportation Research Board, National Research Council.

Kittelson and Associates, Inc. 1999a. TCRP web document 6 - Transit capacity and quality of service manual (Chapter-2). Prepared for Transit Cooperative Research Program, Transportation Research Board, National Research Council. 
Liu, R., and D. V. Vliet,. 1996 DRACULA - a dynamic microscopic model of road traffic. Proceedings of the International Transport Symposium, Beijing: 160170 .

Multisystems, Inc. 2000. Bus Rapid Transit Simulation Model Research and Development. Final Project Summary Report for USDOT/SBIR Phase 1.

Roess, R.P., E.S. Prassas, and W.R.McShane. 2004. Traffic Engineering, Third Edition. Pearson Prentice Hall.

St. Jacques, K. and H. S. Levinson. 1997. Operational Analysis of Bus Lanes on Arterials, TCRP Report 26. Sponsored by The Federal Transit Administration and published byTransportation Research Board, National Research Council.

Transportation Research Board. 2000a. Traffic Analysis Software Tools, Circular Number E-C014. National Research Council.

Transportation Research Board. 2000b. Highway Capacity Manual 2000: Chapter 14-Transit Concepts. National Research Council.

\section{About the Authors}

Abdul Jabbar Siddique (ajsiddiq@connect.carleton.ca) is a Ph.D. student in the Department of Civil and Environmental Engineering at Carleton University, Ottawa, Canada, where he earned his M.A.Sc Degree in 2003. He is working at Carleton University as a Research and Teaching assistant. His research interests are public transit operations, traffic network modelling and simulations and traffic impact studies.

AtA M. KhAN (ata_khan@carleton.ca) received his doctorate from the University of Waterloo (Canada) in civil engineering (transportation). He is a professor in the Department of Civil and Environmental Engineering and director of the Transportation Research Centre, Carleton University (Canada). 